2022 TheoLogica

An International Journal for Philosophy of Religion and Philosophical Theology

S. I. RESTORING HUMAN NATURE

DOI: https://doi.org/10.14428/thl.v6i1.61273

\title{
The Maturational Naturalness of Original Sin
}

\author{
ADAM GREEN \\ University of Oklahoma \\ greenab3@ou.edu
}

\begin{abstract}
A doctrine of original sin or of the human condition generally requires an account of how that sin or condition is transmitted. One would think there are two options for thinking about this. Either original sin is innate or it is acquired. Both would seem to be problematic, the former because all the available options involve untoward metaphysical commitments or implicate God in unacceptable ways; the latter because of the uniformity of the human condition the doctrine requires. In this article, I use conceptual advances within the cognitive science of religion and empirical research to advance a plausible model of what the human condition consists in and how it is passed down.
\end{abstract}

Keywords: Original sin, Transmission of sin, Theological anthropology, Cognitive science of religion

\section{Introduction}

On the Christian story, whatever our individual faults and foibles, our common need of atonement and salvation can be traced back to a human condition we share. Though there may be disagreement over many of the details, that we qua members of the species are disposed to be alienated from God, self, others, and nature should be beyond question. We have "an inherited corruption of nature, a condition which every fallen human being possesses" (Crisp 2015, 264). ${ }^{1}$ Some might endorse a literal Adam and Eve, others not. Original guilt and the fate of unbaptized infants can be set to the side as the more specific concerns of a particular way of building out from the theological consensus that acts as the background to this essay. That a mature

\footnotetext{
${ }^{1}$ Oliver Crisp's definition of original sin in his moderate Reformed and dogmatically minimalist view ends with six more important words "from the first moment of generation" (Crisp 2015, 264; also Crisp 2020, 35). As will soon become clear, though the model presented here can affirm the rest of the formula in that human nature requires a maturational context to develop our agency and, for us, this context is shaped by sin that is thereby passed down to us, there is no straightforward sense in which my model can affirm that last phrase of Crisp's formulation.
} 
human being experiences her moral agency as compromised, her relationships with others including God as wounded, and her realistic hopes of flourishing as fragilethe human condition thus specified is recognizable both across the Christian tradition and beyond it. For the purposes of this paper, let "original sin" designate just this ecumenical intersection point.

Our investigation will concern a specific question: How does original sin spread? This question is largely independent of the specifics of different accounts of original $\sin$. If there is a human condition, it must be passed on by one generation to the next somehow. That specific question on its own is enough to raise something of a theological puzzle. The aim of this essay is to pose and then answer that puzzle in an empirically plausible way. To this end, in the first section of this paper, I will present the reader with reason to think that the human condition would have to be acquired and not purely innate. In the second section, I use Robert McCauley's work in the cognitive science of religion to show how the human condition could be universal without being innate. In short, I argue that original sin is "maturationally natural" for us. Finally, in the third section, I use what we know about "folk theories" and human development to sketch a psychologically plausible view of what exactly is passed down that perpetuates the human condition.

\section{A Set of Bad Options}

How could the human condition spread? Either it spreads by means of something innate or acquired. "Innate" here does not have to involve occurrent states of belief, desire, or intention that are sinful. We need not hobble the innate option with a pessimistic read of neonatal psychology. Original sin could be innate in the form of one or more dispositions that are activated later. An innate option, however, would not be the mere capacity to acquire sinful dispositions nor would just any means of securing the knowledge of future sinning be sufficient. To be innate, we need to posit a psychological structure that already includes inclinations to sin. ${ }^{2}$

If it is innate, then original sin spreads via either the body or an immaterial soul. If an immaterial soul, then either the immaterial souls in question are created directly by God, new souls emerge from new bodies, or previously existing souls somehow produce new ones in a way that parallels the way new bodies are created

\footnotetext{
${ }^{2}$ To borrow from a well-known distinction from Robert Audi, an innate human condition would be more like a dispositional state than a mere disposition to have a state under certain conditions, more like one's ability to remember one's childhood street address than one's ability to commit a new one to memory (Audi 1994). I give credit to Justin Barrett for drawing my attention to the need to make clear what I am and am not assuming by "innate" here.
} 
from gametes. Every fork of this tree of options is puzzling in its own way. In the duration of this section, I want to argue that the most plausible version of each fork of the tree requires us to make sense of how original sin could be a function of nurture, not just nature. Indeed, I will ultimately argue that making a clean division between nature and nurture, the innate and the acquired, is problematic.

One might suppose, though, that original sin has to be innate. Original sin is supposed to underwrite our sharing a spiritual condition as a species. We all share a "solidarity in sin" such that we all experience alienation from God, self, others, and nature; engage in evil actions and omissions; and equally stand in need of salvation. ${ }^{3}$ None of these characteristics are optional; they are, arguably, definitive of the ecumenical core of the doctrine. Yet, human beings differ widely in many ways. The whole point of asserting that there is such a thing as the human condition, after all, is to affirm that along some very important and, indeed, rather encompassing dimensions, we are the same or at least equivalent. Thus, one might suppose that the only way to get the uniformity necessary to speak of a universal human condition would be to place original sin on the innate side of the innateacquired divide. That gives us an initial reason to explore the options on the innate side of the ledger. ${ }^{4}$

\footnotetext{
${ }^{3}$ It is noteworthy that, even in Ian McFarland's 2010 monograph In Adam's Fall which attempts to shift doctrines associated with original sin from the task of historical explanation to that of description of the human condition as we experience it, solidarity in sin in this sense plays a key organizing role. Yet, even if we bracket historical questions such as, say, whether there was an isolated first sin that initiated the human condition, a present solidarity in sin still presumes some substantive explanation of how it could be that we could share such solidarity. Thus, the topic at hand, though related to historical questions of the origin of sin, cannot be bracketed by shifting the task of the doctrine in a more purely descriptive direction.

${ }^{4}$ Likewise, one might think that a view that claims that original sin is not innate must be confused. As a matter of definition, doesn't the word "original" in original sin imply something innate? One might suppose that the whole point of positing original sin is to delimit a view that is supposed to stand in contrast not only with views that claim that human beings are intrinsically good but ones that take us to be the sort of beings that acquire a fault downstream of our common nature (e.g. think of Marx's diagnosis of the way the perversions of capitalism create obstacles to flourishing but ones that are the contingent result of current socio-economic arrangements). No doubt one could choose to define original sin in a way that requires it to be innate. For our purposes, I think that a view should count if it has it that those moral and spiritual effects traditionally associated with original sin can be traced to the historical exercise of the agency of our forebearers, which has produced a single, shared human condition which may be responsive to institutional structures and the like but which is not itself caused by them.
} 
A related but more specific reason can be found in this passage by Oliver Crisp in a context where he is intentionally attempting to characterize original sin in a way that casts a big tent.

[T]here are various versions of the doctrine that attend to a common set of theological themes, though they differ amongst themselves about the precise dogmatic shape of original sin. Nevertheless, all versions of the doctrine that are theologically orthodox must avoid the heresy of Pelagianism, according to which human sinfulness is a matter of imitation not imputation, and is not in principle a foregone conclusion for any particular individual. Also to be avoided is the error of semi-Pelagianism, according to which humans beings are able to exercise their free will independent of divine grace in order to co-operate with divine grace in bringing about their own salvation. $(2015,256)$

Consider also the line of thought developed here by Crisp.

By contrast, the notion that original sin is an inherited moral condition, rather like humans inheriting physical conditions from their parents, seems plausible and is not necessarily unjust ... Similarly, suppose that through some (collective) transgression a first human community is estranged from God. The estrangement, and any consequent moral disruption it causes, may be passed down the generations to later members of the community ... It is not a condition that is picked up by imitation, as the Pelagians averred. It must be transferred .... $(2020,39)^{5}$

The Pelagian worry here, I take it, is that to affirm that the human condition is acquired by imitation is to thereby undercut its being inherited. Why? Crisp says that if human sinfulness is acquired by imitation, it is not a "foregone conclusion" that one will inherit it. Thus, the thought seems to be that the person doing the imitating is already acting out of an untainted human agency that they then bring to the task of imitation. They are untainted prior to imitating, and thus have not inherited the human condition. If that's so, though, it would seem that it is up to them whether to imitate or not. Hence, it would not be clear why we were justified in affirming humanity's solidarity in sin. If, however, it was not up to the imitator whether to imitate human sinfulness, if it was somehow guaranteed, then it may once again be a foregone conclusion that human beings are sinful. In which case, it

\footnotetext{
${ }^{5}$ Thomas McCall similarly singles out Pelagians and Semi-Pelagians for disapprobation when it comes to original $\sin (2019,182)$. His concerns, however, seem to lie elsewhere than with qualms about imitation (cf. 155, 161). In fact, the only place where I see a reference to imitation in his treatment of original sin is in a quote from Zwingli whom McCall does not think a Pelagian (157).
} 
would be a lot less clear why Crisp should exclude the imitation option from his big tent. Thus, we shall start with the innate options, but ultimately, I will be pushing an option that includes imitation as well as other means of acquiring the human condition in a way that is not up to the person in the sense at issue here.

If original sin is innate, then one option is to blame the body, specifically our genetic inheritance. One might, for instance, suppose that the fall changed the body. ${ }^{6}$ If God creates human beings good but we culpably damage that design, why not think we could pass down our condition genetically? If one were able to get ahold of a sample, a pre-fallen eyelash trapped Jurassic Park-style in Edenic amber perhaps, then sequencing it should reveal some important genetic difference (though we should look at cytoplasm and mitochondria as well, I suppose). Taking this option seriously would commit one to the thesis that if one but knew how to go about it, one could find the nucleotides getting us in all the trouble and perhaps solve the human condition with some creative germline editing. We don't need an itinerate rabbi on a cross; we need a geneticist in a lab! As Hans Madeume remarks in a similar context, a "biologized hamartiology conflates the doctrine of creation and the doctrine of $\sin ^{\prime \prime}(2020,31) .^{7}$ The point is not one of theological bookkeeping. The kind of effect in question, a universal genetic change in a species dramatically affecting their experience of agency, is not a good match to individual acts of agency as we experience them. If one was looking for an agent who could explain such a widespread genetic change, God is the more natural agent to pin the change on with all of the attendant theodical issues that would entail. Moreover, just as the effect seems an ill fit for the supposed cause, just so the solution, namely incarnation and atonement, similarly seems a mismatch.

One might suppose that a more gradualist explanation of the human condition in genetic terms has more plausibility than a fall happening at one time. We know that genetic changes over generations can cause dramatic differences discernible at the macro-level that are quite wide-ranging for an organism. If, to explain the emergence of a human condition, we use the long timescales of gradual evolutionary change but we also disperse that process over a widely distributed population, then

${ }^{6}$ Though Augustine's thoughts on the seminal transmission of sin are hardly popular nowadays. One might, nonetheless, see a precedent here for a genetic view of the transmission of sin. Pier Beatrice's description of Augustine's view seems apt when he says, "The transmission of hereditary sin is so concretely connected to the sexual sphere of procreation that one could compare it, for Augustine, to the transmission of gout from father to son, or of other kinds of diseases that pass from parents to children in the reproductive process" $(2013,68)$.

7 Madeume is commenting on attempts to accommodate evolutionary theory that he finds excessive because they introduce evil into the cosmos before the fall. I am not concerned about evolutionary theory in that way. 
insofar as one has genuinely made room for essential changes to our moral and spiritual condition, one undercuts the possibility that this gradual change happened in an equivalent way for the whole species. Appealing to gradualism helps explain how genetic changes can explain radical changes in behavior including, presumably, moral behavior and religious practice. Insofar as the mechanism in question is producing and selecting amongst variation, however, the mechanism itself would undercut the idea that what is selected is a common human condition. I suppose one could say that there is some selective pressure winnowing out more morally perspicacious starting points to keep human beings collectively bound to the same condition wherever they happen to be, but that would itself be a pretty mysterious claim pushing us away from purely innate factors towards acquired ones. Indeed, the most plausible candidate for an accelerator of selection pressure that can operate over a wide range of ecological niches is culture (cf. Boyd 2018; Henrich 2016; Laland 2017).

Now, of course, one might protest that original sin could supervene on biology without our genes having to be different. One might, for instance, think about epigenetics and the way that organism-level systemic factors and interactions with the environment can influence what proteins are made when and the like. For any bad action, one can, in principle, find a correlated biological description to pair with that bad action that gives a biological picture of an organism engaged in the action that we are judging to be bad. That macro-level biological picture can itself be resolved into a still more fine-grained biological picture at the micro-biological level, a microbiology gifted to one by one's biological parents but activated in a way that is dynamically responsive to extra-genetic factors.

Why not think, then, that the body carries original sin not so much in the human genetic sequence, though some degree of selection is possible here, as in how genes are used? Whatever objections such a proposal might engender, it is sufficient for our purposes to note that it would, once again, push original sin back in the direction of being acquired rather than innate. For, if a genetic influence on wrongdoing is essentially dependent on, say, environmental influences on gene expression, then whether one experiences such an influence or not depends on the context one is placed in, and consequently, we are left again with the puzzle of how there could be a single human condition (or a set of equivalent ones) given the wide variety in the epigenetic factors that we experience. ${ }^{8}$

${ }^{8}$ It should be noted that it is possible for an epigenetic alteration of a gene's behavior to have a transgenerational effect (Francis 158-159). So, an epigenetic effect in one person can be the relevant explanation for the altered gene behavior of a descendant. If this is a change in gene expression and not a change in the genes themselves, one still has to ask, though, how thorough-going and how long- 
If one's anthropology allows for the existence of an immaterial soul, then we have more options for how it could be that original sin is innate. The first such option is to say that God specially creates a new immaterial soul for each individual person. Whatever reasons there may be to posit specially created souls, in this context, however, it should be obvious that there is a problem with combining that view with the further thesis that original $\sin$ is innate and tied to an immaterial soul. Combining these views would require God to create a soul in a fallen form. This would involve more than God simply preserving the cosmic order, now fallen, within which new human beings arise. Instead, God would have to be responsible for directly bringing into being something flawed, where that flaw includes some kind of disposition for the being in question to become alienated from God-self. In effect, it would not be the case that Adam \& Eve or some early hominid population's misdeeds started a domino effect that carries on down the generations so much as that God, as it were, knocks over each domino as it is created by creating human natures already warped, though perhaps as some sort of punishment for past human misdeeds.

Now, of course, one could hold that God creates for each human being an immaterial soul without also positing that the soul created is fallen. There is a certain tragic elegance in positing both that God is so invested in us as to create each human soul directly and yet refuses to insulate us from our species so as to forestall our participation in the human condition. It is hard to imagine, however, how one could have this combination of views without, once again, making original sin something that is acquired rather than innate, especially if one has already exonerated the body as the carrier of the human condition. As Hans Madeume puts it, "creationism implies that God is responsible for souls being born sinful or that souls become sinful by coming into contact with the body" $(2020,30)$. Thus, for God to "knit us in our mother's womb" and create something that is only good, it looks like we would need original sin to overtake us after we already exist.

Consequently, if we want to affirm that original sin is innate, we are left with the possibility that human beings have an immaterial soul but that it is not specially created by God. There are two ways that this could work. One would be to endorse an emergent dualism. Whether we make the immaterial component of a human being a property or a substance, we could have an anthropology on which a physical system, the body, somehow generates something immaterial. On this option, either the carrier of original sin really is the body and thus we go back to a prior option or

lasting that change could be without carrying forward some factor that renews the epigenetic effect environmentally. 
else we have to explain not only how something immaterial could emerge from something material but also how something innately fallen could emerge out of something not fallen. ${ }^{9}$ If the emergence of a person or of a person's moral agency is partly dependent upon or influenced by external factors, then we would have a ready explanation for how an emergent soul could be fallen without that moral condition being reducible to the original state of the emergence base, but that, yet again, would be to tack back in the direction of original sin being acquired. ${ }^{10}$

Finally, one could hold that original sin is transmitted via an immaterial dimension of ourselves, that it is innate and not acquired, and that this immaterial part neither emerges from the body nor is specially created by God. The resultant view would be a kind of anthropological occasionalism. A new human being would gain a physical body care of her parents via a physical process, and she would get an immaterial part, a soul, via a non-physical process also care of her parents. ${ }^{11}$ Two fallen beings could pass on a fallen nature and do so without curious commitments on the level of genetics. Why an immaterial process is initiated at the same time as a physical one that eventuates in a new human is, of course, a complete mystery though, and, unlike with physical genetics, we have no principled way of thinking about heritability for this hypothetical immaterial process.

Though this option pays the highest price in mystery, it at least avoids the clear problems faced by the other views. Avoiding problems associated with the other

\footnotetext{
${ }^{9}$ Of course, the traditional puzzle surrounding the first sin already must make sense of how an unfallen nature could produce a fallen one, but in this case, we would not even have a will to appeal to in an attempted solution because an unfallen, non-agent would have to serve as the emergence base for a fallen agent.

${ }^{10}$ I do not pretend, of course, that all the views that fall within this category are not importantly different in many respects. Perhaps one finds it more empirically plausible, for instance, that the brain in virtue of being a complex system, could have system's level features that count as emergent because they are not reducible to the properties of the physical constituents when taken outside that dynamical system. Someone else might mean by an emergent view to posit something that does not reduce to its constituents and their properties in a stronger sense. So be it. I do not trace the options further here because I do not see how they would affect the question of whether the human condition is innate or not. Of any given option, one will either make the physical the carrier of original sin, at which point we return to the first fork of the discussion, or we mysteriously posit that an untainted emergence base can produce a tainted emergent property or substance without the intervention of some external factor causing the problem on pain of original sin not being innate and having to count as acquired. I thank peer reviewers for flagging the need to show some awareness of the diversity of these camps.

${ }^{11}$ Technically, one can imagine immaterial souls coming from something other than God, the body, or one's parents, but aside from creating a novel fictional universe, I don't know why anyone would endorse such a view. Apologies for neglecting Thetans here.
} 
views, however, is the only real reason to endorse a traducian occasionalism, and thus, improving any of the other options would ipso facto make that other option preferable. After all, it is not as if there is something that we know about this view and its processes that underscores our confidence in its ability to explain how we could all share a human condition. A mysterious soul-begats-soul process can be easily enough imagined as passing on no moral condition at all. Likewise, we have no mechanism here that excludes the influence of environment and context. What we know of influence at the agent-agent level is all on the acquired side of the naturenurture divide. In fact, if we ignore for the moment that we are trying to find an innate option, we have very familiar ways of thinking about how one's parents qua agents can influence a child, and indeed do so very early. What we know about abuse, neglect, and attachment shows that a child's starting point in life can, obviously though also tragically, be radically impacted by how its caregivers relate to the child early in life. These interactions can shape the form that agency takes as it emerges. A traducian occasionalist, though, could not appeal to anything like that without, once again, making the human condition in some significant sense acquired rather than innate.

Thus, I contend we have ample reason to think anew about whether the human condition can be both universal and also not innate. In the next section, I will turn to the cognitive science of religion to show how this could be.

\section{A New Option-Maturational Naturalness}

Robert McCauley, a prominent theorist in the cognitive science of religion, is unsatisfied with our tendency to divvy up behaviors into nature and nurture, innate and acquired (McCauley 2011). The reason is that he sees a need for three categories, not two. ${ }^{12}$ We have, to be sure, innate traits that don't seem to depend on context in any robust sort of way. Newborn infants do not emerge into the world capable of fending for themselves, but they certainly have capacities to orient and interact with their environments, which allow them to thrive as infants. One also finds human traits and behaviors that are far from universal and require practice, often practice in special conditions, to exhibit. They can become second nature, a kind of "practiced

\footnotetext{
${ }^{12}$ I find McCauley ambiguous as to whether he wants maturational naturalness to include the traditional category of innateness or act as a third category. If the former, then one would still need to distinguish between traits that require a certain path of normal development to be realized from ones that do not. One would find a way to three categories by a more circuitous route, and in any event, McCauley's focus in his discussion of maturational naturalness is on traits that emerge in typical human development. I simplify the presentation here.
} 
naturalness," but one needs no special reason for their absence. McCauley draws attention to contemporary science for examples of practiced naturalness (83-143). To do science, one must test one's hypothesis in a principled manner that often runs athwart one's natural instincts. This consists in not only unnatural efforts, such as John Flamsteed's hourly measurements of the planets and stars over the course of forty years (120), but in forms of thinking that discount our cognitive heuristics in favor of more abstract standards like statistical robustness (122-137). McCauley doubts that many scientific practices become fluent enough to merit the label "natural," but if any do, they certainly are acquired through unusual personal dedication and cultural conditions. In between these two, practiced naturalness and that which is innate in the conventional sense, one finds what McCauley calls "maturational naturalness." In this section, I will motivate and nuance this category and then apply it to original sin.

Highlighting the interminable debates engendered by the question of whether traits are innate in the sense traditional to innate-acquired debates, McCauley comments on and delineates what it is for a trait to be maturationally natural as follows.

Crucially, none of the conflicts about innateness undo the relevant capacities' maturational naturalness. Cardinal capacities such as recognizing faces, uttering comprehensible sentences, and walking, like all cognitively natural systems, operate automatically, unreflectively, and (mostly) unconsciously. In addition, they possess other features peculiar to maturationally natural systems.

(i) They prevail in the human cognitive economy before humans can remember that they do.

(ii) They concern problems that are so basic to human survival that

(iii) possessing these maturational skills and knowledge qualifies as normal development for members of our species and in some especially fundamental cases (for example, locomotion), what counts as normal development for members of other species as well.

(iv) Their appearance does not rely on either schooling or instruction or artifacts. (72)

Maturational naturalness concerns those behaviors and acquired traits that will ordinarily develop for a person without special training or practice. They may take different forms across different cultural and geographic contexts, but they are typically tied to re-occurring human needs and situations. ${ }^{13}$ They track the solutions

\footnotetext{
${ }^{13}$ These situations need not come solely from without; they may themselves be partly or wholly of our own making. Thus, nested maturational naturalness is possible. For example, given that we
} 
to universal human needs that humans find intuitive given the interaction between our innate endowments and human environments. Just as a Martian might think human beings look very similar despite the differences we notice (e.g. "mid-size, hairless, tailless apes within a relatively confined range of brain-body volume ratio"), so too our human contexts have more in common than one might ordinarily think.

Human beings have many of the same needs as other animals - the need to eat, avoid temperature extremes, and reproduce and raise young, for example. As our Martian anthropologist would tell you, though, our biology constrains what solutions to these problems are feasible for us. Given the interplay of our natural endowment and environmental constraints, we would expect the same kinds of solutions to be hit upon by distinct human populations facing the same kinds of problems. This should apply at various levels. For example, it shouldn't be surprising if different human cultures found in cold environments dress in animal furs to stay warm. Given human needs and environmental opportunities, one can, if not guarantee, at least expect certain ways the two will interact.

These dynamics extend beyond the generation of material artifacts. A capacity for language appears to be innate. The way that language facility develops depends on the social environment. Language is modeled and taught, but it is also just absorbed from being a human being living around language-using human beings. ${ }^{14}$ The shape of that social environment is, itself, responsive to the physical environment as the famous example of Inuit words for snow illustrates. Likewise, the beliefs and norms that are common across a population will reflect the fact that it is human beings with their needs, interests, capacities, and environments which are forming these beliefs and endorsing these norms. Thus, for example, it should come as no surprise that taboos form cross-culturally that relate to how one ought to relate to dead bodies. Given the human need to not contract whatever killed someone else, and given our status as language users with the rational and imaginative capacity to conceive of invisible agents or other invisible causal factors, it makes sense that we would find in culture after culture strong regulations concerning how one is to interact with a dead body using stories that reinforce how touching a dead body could be bad by taking us beyond what we see. It is tempting to focus on the diversity amongst the details of particular taboos and their justifications, but that diversity at the level of

are a fire-using species, it makes sense that our biology would come to be more dependent on cooking technology, which in turn would lead to the maturational naturalness of increased consumption of plants that are amenable to being processed through ubiquitous cooking technology like fire.

${ }^{14}$ For an excellent summary of the cross-cultural and cross-species investigation of human communication, see Tomasello 2019, 91-133. 
detail masks a fair bit of functional overlap in how taboos about dead bodies actually work and what needs they address.

For McCauley, what is subject to practiced naturalness need not be reflective and intentional. It can be habituated. It can become second nature, though rising to that level will typically require a formation process that involves explicit instruction and cultural scaffolding. What we learn by practice in this way is often a cultural innovation with a particular history and a localized reach, dependent on institutions and often on artifacts used in specialized ways. It is typically harder to find analogues in other species for our exemplar instances of practiced naturalness. What is maturationally natural, by contrast, he associates with what no one invented, what does not depend on particular artifacts to emerge, what is more likely to be shared with other species, and what does not require explicit instruction (29). His exemplars, like walking or discovering object permanence, are mastered so early and effectively that we don't remember learning them as adults (72). We know that there was a time when we lacked these abilities, and further we know that their development can be thrown off. Yet, we have a hard time not thinking of them as innate and, for the same reason, we easily fail to notice that they develop in interaction with an environment which plays a role in development.

The story about original sin that I will develop will involve something becoming maturationally natural that need not be. I will not be claiming that the human condition was inevitable, for example, given climactic traditions, human biology, and flora-fauna distributions. To set up this account, it is helpful to think through the boundary between what is maturationally natural and practiced naturalness with some nuance. It is tempting to divide beliefs and behaviors sharply as being either one or the other, as being maturationally natural or practiced. It is tempting in part because that is how the traditional division between nature and nurture has often been treated. There is some utility in focusing on cases where practiced naturalness diverges sharply from what is maturationally natural, especially if one is concerned, like McCauley, with the fragility of something like science which rests on an especially high degree of "unnatural" belief and practice (2011, 83ff). What I think is more accurate, though, is to envision a structured continuum. We have natural endowments which do some things automatically. If the environment is not adverse to it, then they respond adaptively to the most basic and general features of the environment, developing ways of being in the world that are adaptive at that general level. The more friendly the environment is for specialization, the more one can fine-tune and build on one's natural capacities, which can include refining or contradicting earlier and more deeply ingrained patterns of thought and behavior to an extent. The farther we go towards specialization of our basic capacities, the less 
universal development becomes and the more it is geared towards a particular environmental, social, technological context. After all, practiced naturalness doesn't come from nowhere. One has to bend the innate and the maturationally natural to the actions that become the habits that create practiced naturalness.

Further development doesn't necessarily contradict or build atop what is more maturationally natural. Rather, it can take the form of giving the maturationally natural further outlet and specificity. Consider, once again, language. Neither Mandarin nor King James English are innate, but arguably, the capacity for language is. Speaking one's mother tongue, that general capacity, is maturationally natural. Yet, the exact way that capacity is realized, as speaking Mandarin rather than Catalan for instance, is a function of context, especially social context. Furthermore, language is not something one simply has once one is past the first few years of life or is biologically mature. Though one's early language experiences have a disproportionate influence on one's linguistic career, life experience adds new words, new constructions, new dialogue schemata, and possibly new languages as one explicitly or implicitly tailors one's language use to track one's communication needs. Thus, while speaking one's mother tongue is maturationally natural and the capacity to do so is innate, speaking it the way people in one's geographical, social, and vocational position speak has elements of practiced naturalness to it. Yet, one does not necessarily shift back and forth between a maturationally natural mode of speech and a practiced kind. Rather, it is natural in the maturational sense that one develops one's linguistic capacity in a way fit specifically to one's particular context. The fact that there is a structured continuum from the innate to the maturationally natural to practiced naturalness in McCauley's sense is also clear from McCauley's other special interest, religion (2011, 145ff). Insofar as alienation from God is supposed to be an important part of original sin, it is worth developing the application of maturational naturalness to this domain. Unlike science, which McCauley thinks of as exemplifying practiced naturalness, McCauley argues that religion is maturationally natural. One is no more born a Buddhist, a Christian, or a Muslim than one is born speaking Mandarin, Arabic, or the King's English. The growing field of the cognitive science of religion, of which McCauley's contribution is a part, has built up a diversity of evidence that suggests that religion is, if not innate, at least something we readily acquire (this is the dominant theme, for example, in Barrett 2004 and 2012). That is, beliefs, intuitions, and practices associated with religion are readily acquired and cross-culturally well-represented. We readily attribute agency and purpose to the movement of more than just animals (cf. the classic study Heider and Simmel 1944). In fact, many have thought that, for evolutionary reasons having to do with predation, we should have a natural 
disposition to over-attribute agency (Guthrie 1993). We are experts at social cognition, and often prefer social explanations to probabilistic or merely mechanistic explanations (cf. Cosmides and Tooby 1992 discussed by McCauley on his 55-57). These preferences for social explanations extend to the explanation of events in terms of fortune and misfortune (cf. Boyer 169-202). We have a hard time understanding the limits of the knowledge and agency of others early in life, and many god concepts fit our procrustean experience of the agency of others (Barrett and Richert 2003). Some have argued that, as human beings come to live in dense social units in which cooperation is paramount but in which there is enough genetic diversity for it to be tempting to promote one's genes at the expense of one's cooperation partners, it is adaptive to believe that there are morally interested superagents out there who see the rule-breakers and the virtuous, punishing and rewarding accordingly (cf. Norenzayan 2013). And so on.

Yet, to whatever extent religion may be maturationally natural as McCauley says, it is just as important that religion gets expressed with specificity, through detailed practices and belief systems that are grown into in a way that is not universal but which fit the particular needs and experiences of individuals and their groups as played out in their particular environments. Just as we don't speak "mother tongue" but a specific language that is our mother tongue, so too with our "mother religion." Moreover, there are aspects of religion such as canon law, religious art and architecture, and professional theology that are excellent examples of practiced naturalness. These more specialized articulations of religion need not be thought to be causally or functionally insulated from the maturationally natural elements of religion. Consequently, McCauley's thesis about the maturational naturalness of religion could be accurate in much the same way that speaking a mother tongue is maturationally natural, and yet there could be a lot of difference to be found from religion to religion just as there is a lot of diversity amongst human languages. Some differences across religions (or languages) will concern parts that one has that another doesn't have, as when we contrast tonal and non-tonal languages. Other differences, however, will concern the different expression of a common feature, such as the way that linguistic developmental milestones within the first five years of life have a great deal of cross-applicability to children learning any mother tongue, even though what each child learns is given shape by the particular character of the language in question.

One common feature across religions relevant to our purposes is the way in which the maturationally natural expression of religion, though in one sense acting as the foundation of the moral codes and explicitly articulated theologies of religion, also appears to pull in the direction of theological incorrectness, inconsistent fidelity, and 
moral mediocrity. Human beings may have a maturationally natural leg up on conceiving of the world as populated by super-knowing, super-powerful, invisible, morally interested agents who are always potentially present. The concept of God common to the major monotheisms builds out from these maturational starting points to an omniscient, omnipotent, omnipresent, omnibenevolent but holy, transcendent but immanent spirit. Likewise, we have a maturationally natural pull towards conceiving of the gods as policing expressions of self-interest that impose unacceptable costs on kin and tribe. Likewise, there is a pull towards conceiving of the gods as requiring costly commitments of time, memory, and resources. The major monotheisms extend these natural starting points to articulate a moral code that applies, in principle, to all of God's children. Salvation may be in one's selfinterest, but it involves a process of formation that conforms the interests of the believer to those of the divine. Moreover, though distinctions may be made between empty rituals and true religion, the claims of a major monotheistic religion on one's time, resources, and so on is, in principle, total. Complete life transformation is the goal.

Though religion may rest on the foundation of maturationally natural elements, what is also true is that the cognitive science of religion gives us ample reason to think that, though there may be a continuum here, human beings routinely deviate from the more demanding specifications and standards of official religion. This may come in the form of cognitively relating to God through more intuitive but less theologically sound anthropomorphic terms (Barrett and Keil 1996; Barrett 1999; also Slone 2004). We frequently treat God or the gods as functionally a dominant individual to be recruited to our private interests or else appeased and ignored. Indeed, although one's official religion may specify means for courting good fortune and avoiding misfortune, religious specialists whose function is to ward off misfortune are ubiquitous and often have a tenuous or even non-existent relationship with official religion (cf. Boyer 2019). We manage our investment in religion in a way that is relative to payoffs in social standing, happily gaining credit for putatively costly displays that are not costly for us. The moral behavior of the average religious person is more likely to yield evidence of "mixed traits" rather than a recognizable approximation of the moral character implicit or explicit within a religion's moral code. Social contexts in which the need to rely on religion for social cooperation is masked by stable secular institutions, see a related drop in average religious commitment, practice, and fervor (Zuckerman 2020; see also Norenzayan 2013, 170-192). Thus, on the one hand, religion appears to be maturationally natural, but, on the other hand, religious failure, or at least underperformance, appears maturationally natural as well. 
We now have a sufficient foundation to put forward the main suggestion of this section. I claim one can best make sense of the doctrine of original sin by positing that it is maturationally natural. It isn't carried by our genes in any deep sense. It is not communicated mysteriously, one immaterial soul to another in the womb. It certainly isn't placed in the soul by divine fiat. Rather, if one takes human nature together with what human environments have in common, the result is a human disposition to be alienated from God, self, others, and nature. The exact forms this alienation takes will vary depending on context, and it may even be that the relative priority of these categories will vary (e.g., maybe some cultures are more alienated from nature than others). But normal human development is the culprit.

One might wonder, at this point, how this claim helps. If original sin comes from the interaction of human nature and human environments, one is still, one might think, appealing to things that God is supposed to have created good. Yet, it is important to note that the environment in which humans develop and express their agency isn't just a physical environment. It's a social one. McCauley associates the maturationally natural with that which does not require explicit instruction or technology. Yet, it does not follow that what is maturationally natural is asocial. Return again to language. Without a social context, one would not learn to speak a mother tongue. Learning to speak is flexible concerning the kinds of social environment in which it is realized, and the way that one develops language is responsive to instruction and technology. Yet, at its most basic level, language acquisition is both thoroughly maturationally natural and thoroughly social. Indeed, it is not hard to imagine scenarios in which one's language might develop in a way at variance with the explicit instruction one is given because the patterns of usage that imbue one's context of development are at variance with how one is overtly taught to speak.

In section I, I motivated a theological puzzle regarding how original sin spreads. I problematized innate options, while underlining why one might have thought that original sin could not be acquired rather than innate. In this section, I have developed the idea of maturational naturalness and why one might think that original sin fits into this category. In the next section, I add a layer to the model by developing a suggestion on what exactly would be spreading on my view.

\section{But What is Passed Down?}

Ideas spread, but not all ideas spread equally well or, once spread, have staying power. To understand which ideas spread and how, it is helpful to introduce the idea of folk theories, which have an important influence on which ideas we attend 
to and what we do with them. Folk theories, themselves, are maturationally natural in part or whole. Thus, they are at least in part acquired while still playing a fundamental role in what else we acquire. In this section, we will explore the link between folk theories, counter-intuitiveness, and psychological salience. Having done so, we will then back up to think about how original sin might be passed as a maturationally natural framework of salience that we model and thereby spread to successive generations.

A belief in object permanence is maturationally natural. There comes a point, a very early point, in the development of a child where they will show surprise and increased attention when an object is made to look as if it has disappeared (cf. Baillargeon and DeVos 1991). Once learned, the child will treat all kinds of objects as having permanence. It becomes domain general. The world around the child takes on a different character as the child comes to treat it as systematically populated by permanent objects. Object permanence isn't the only phenomenon like this, however. The child acquires expectations for how physical objects normally behave. This set of expectations guide the infant's interactions with its environment and guide the development of its capacities. They, for instance, form the cognitive environment in which motor planning occurs and new actions are practiced. New abilities are acquired in a cognitive context that implicitly contains one's expectations for how the world will unfold under one or another way of interacting with it. These systematic expectations about the behavior of physical objects may not be consciously articulated, but nonetheless they are called folk physics because they function almost like a theory of physical reality. If a theory, it would be a rudimentary theory, grossly inadequate for doing actual physics, and indeed one can often predict the errors we make and the illusions we are subject to by focusing on our folk physics.

We do not only have a folk physics, however. It looks, for instance, like we have a folk biology having to do with our expectations for bodies and for animals. We expect an animal new to us to, nonetheless, pursue food, avoid threats, and make offspring that look like itself and not other creatures. Likewise, we have a folk theory of mind, that is, expectations for what has percepts, beliefs, and desires, and what they might be in various conditions. Psychologist Elizabeth Spelke uses the term "core knowledge" to describe this set of early developing but enduring folk theories (Spelke and Kinzler 2007). Exactly how many folk "theories" we have is not canonical, but the idea is that we acquire basic convictions about how the different parts of our experience work which can be coarse-grained but are deeply functional. Moreover, insofar as folk theories depend on experience but appear universal, are 
hard to remember acquiring, and often exercise an automatic influence on our experience, they seem maturationally natural.

We have the capacity to think in terms that violate our folk categories, however. We can, for instance, imagine a tree that can read the thoughts of squirrels on every other Tuesday but forgets what it learns by Wednesday. That's a pretty useless idea, and hard to remember with fidelity. We can consider it, though, despite the fact that it is violating our expectations for more than one kind of folk theory. We have some reason to believe that an idea that violates our intuitive categories, our folk theories, actually enhances its memorability and its tendency to spread with fidelity all other things being equal, but only if the counter-intuitiveness is limited (cf. Boyer and Ramble 2001). For instance, a tree spirit that reads thoughts and communicates them to others is much easier to remember. A mind-reading tree is also much more likely to grab one's attention and to spread due to a second factor, namely, relevance to our practical concerns and the socially contextualized achieving of them. A tree spirit that could tattle on you is more plausibly relevant to your practical concerns than a tree that is an ineffective collector of Squirrel-ine trivia.

Our folk theories do not develop independently of our practical interests. A child, in acting on and being acted upon by a physical world, experiences the patterns that become a folk physics. In being engaged by and engaging with others, we develop a theory of mind, and indeed, the traumatic effects on development for theory of mind caused by neglect (though not only for theory of mind) are well known. The content of folk biology tracks those generalizations useful for making sense of one's interactions with plants and critters. Even for maturationally natural beliefs and behaviors, a relative independence from explicit instruction does not make them float free from either practical interests or social modeling. Consider, for instance, social referencing at 10 months of age in which the child, upon experiencing a novel stimulus, like a dog or a robot with flashing lights, will check its caregiver's emotional response and take that response, whether positive or negative, as a cue for how to feel about the new experience it is having (cf. Striano and Rochat 2000). The extent to which a child's experiences are specially curated, obviously, can vary from one cultural context to the next, but what is universal is that early formative experiences shape our expectations which become our folk theories. Moreover, many of these experiences occur in and are influenced by a social context. ${ }^{15}$

${ }^{15}$ The way in which human development, including the development of characteristics unique to human beings in kind or degree, is dependent on social context without being dependent on the kind of overt instruction that varies significantly from culture to culture is a special emphasis of Michael Tomasello's 2019 monograph Becoming Human. 
Indeed, the number of folk violations cannot be the whole story about how often or how successfully ideas spread because what we attend to and what we communicate is highly dependent on our practical interests and the contextualization of those interests in a social context. Both intrinsic and extrinsic motivation influence attention and memory (cf. Robinson et al 2012). Consider, for example, inattentional blindness. In a famous study (Simons and Chabris 1999), the subject is instructed to count the number of times a basketball is passed between the members of a group of people. We have, in effect, artificially defined the person's practical interest within the context of the experiment and done so socially. While so attending, most subjects fail to note what should be a violation of how experience normally goes. Someone in a gorilla suit wanders into the middle of the visual field and dances or waves. The subjects often do not notice. The attentional system is not neutral, but it is also socially cued in a way that sets its attentional priorities.

It is worth noting that it isn't just the case that we are more attentive to and receptive of category violations. Consider, for instance, the phenomenon of imaginative resistance (Gendler 2000; Liao, Strohminger, and Sripada 2014). If you are told a story about a happy-go-lucky child molester oppressed and misunderstood by a rigid, moralizing world, then you may well experience yourself resistant to suspending disbelief in your engagement with the story. The moral logic of the fictional world is repellant. One may be able to overcome one's instincts here, but one nonetheless feels resistance. One feels an automatic resistance even though one knows one is only reading a fiction. Likewise, consider Haidt's experiments on disgust in which participants have a hard time giving a worked out rationale for their strong intuitive rejection of certain actions (cf. Haidt, Koller, and Dias 1993). Being asked to imagine having sex with a dead chicken is, among other things, a violation of one's folk expectations for sexual behavior. Qua folk biology, sex is supposed to be about procreation, but theory of mind and folk morality are no doubt in play as well. It may be, unfortunately, a memorable example, but one does not orient to it because of surprise at what is possible, so much as one orients to the category violation with a resistance embodied as disgust.

Big picture-wise then, our basic expectations for how the various aspects of our world work, our folk theories, are not just a set of beliefs amongst others. Rather, our folk theories form a matrix against which things stand out as either especially worth paying attention to or else worth resisting as suspect. It is hard for us to make sense of what deviates from our folk expectations too drastically. And, in fact, though a deviation from our ingrained expectations might engender interest or be memorable, we do not necessarily orient to deviations out of interest. We may orient with resistance, suspicion, or hostility. 
Return, then, to the topic of original sin. It is supposed to explain a far-reaching disposition to become alienated from God, ourselves, our neighbor, and nature. In earlier sections, I made the case that we should think of it as socio-cultural but maturationally natural. We are now in a position to add another layer to the model. Suppose that original sin is an over-arching salience framework that is modeled for us by other agents. Much like a folk theory is a set of expectations for how the world unfolds within which we situate our interactions within a particular domain, so it is here that our expectations for how to navigate the world of value is formed by how we experience people modeling what has value, how much, and in what circumstances.

Other people model the relevance of other people, the natural world, and religion as pertaining to their self-regarding projects. They treat earthly goods as more important than spiritual goods and the individual good as more important than the common good. Dominance is treated as desirable and vulnerability as undesirable. The natural world may, at times, be feared, but it is also there to be exploited. In short, whatever cultural innovation may be present to manage or shape it, the thesis is that the framework within which human beings make sense of the relevance of behaviors and events is internalized from persons who model a disordered way of relating to all these things, which shapes our developmental context. These models are self-reliant and self-absorbed enough that we do not naturally develop a default reliance on God, a trustful communion with our neighbor, a harmonious relationship with nature, or, indeed, an honest acceptance of the self.

Once again, what is maturationally natural may be exemplified on the ground in a way particular to its context. In the Kalahari Desert, speaking one's mother tongue may involve a tongue click that itself is far from a human universal, but at a higher level, one can speak of the universal human disposition to speak a mother language. Similarly here, the jagged articulation of our brokenness as a species may differ from culture to culture, but if original sin is true, it must come with a disposition towards alienation towards God, self, others, and nature. I don't think it is hard to imagine an embodied way of life informing development, acting as a kind of salience framework within which typical human experiences are located and made sense of. We need nothing especially spooky for this hypothesis to be true, no hidden taints or fatal nucleotide sequences. We just need a social species run amok.

\section{Conclusion}

In conclusion, if original sin acts as a salience framework, leading us to attend to some things as relevant to our interests while leading us to resist others, then one 
thing we ought to expect is that we have a natural tendency to resist the association of flourishing with vulnerability, trust, and dependence. This resistance need not come at the level of reflective, effortful styles of thought. After all, the hypothesis is that original sin is maturationally natural, which is more associated with automatic, instinctive processing. To put it in the terms of dual processing theory, the resistance might well come primarily at the level of "system 1" rather than "system 2."16 Rather, if original sin is true, I would expect human beings to have both a natural attraction to or longing for a flourishing that takes exactly this form while also being powerfully resistant to it.

To return to Oliver Crisp's concern that imitation cannot be the mechanism by which the human condition is passed on lest we fall into the embrace of Pelagianism, we are now in a position to see why inheritance and a kind of imitation are perfectly consistent. Imitation is not simply something agents do; it is a means of acquiring agency. We become full human agents by navigating social contexts that both frame our development and provide models for it. The fault of Pelagius here may not have been an over-emphasis on imitation but an underestimate of how early, thoroughgoing, and involuntary imitation and like mechanisms shape the human person.

To take a final theological turn, one might suppose, then, that one of the functions of an incarnation is modelling a different way to be human. Such a trope is common enough in theology, but if original sin is passed along not by genes or through immaterial virology but through modelling and development, then the presence of a different kind of model makes it clear how the incarnation intersects not just with our voluntary sins or our debt of punishment, but how incarnation interrupts the transmission of original sin. ${ }^{17}$ Moreover, one is given a new way of looking at the

${ }^{16}$ This is not to say that "system 1" is sinful while "system 2" is not. Many of our God-given good instincts would operate at a system 1 level, and the rationalization of bad behavior thoroughly implicates system 2. The classic introduction to dual processing theory is, of course, Kahneman's Thinking Fast and Slow.

${ }^{17}$ On this model, one might wonder what one should make of Jesus' status vis-à-vis his having a human nature and developing in a typical human context. To do justice to this topic would require its own essay, in this context I say only two things. First, even though others might not identify it as the medium by which original sin is passed down, anyone who allows that our sinfulness expresses itself in ways that affect the development of children will be stuck with the same problem to overcome, and that should be everyone. Second, I see the issue as exactly paralleling the topic of how Christ could experience temptation qua human being while being unable to sin qua God. However one answers the puzzle of how Christ could experience temptation has a readymade solution mutatis mutandis for this worry as well. My own inclination is to say that part of Christ's being tempted in all ways as we are (Heb 4:15) would have to include temptations particular to development but that it is only in virtue of Christ's divine nature that he is not warped by his human developmental context. Likewise, to the person who would push the Pelagian worry through the example of Christ by saying 
incarnating task of the global church, as something meant to be a counter-culture articulating of a new way to be whole and human in each cultural mother tongue of our species.

\section{Bibliography}

Audi, Robert. 1994. "Dispositional Beliefs and Dispositions to Believe." Nous 28(4): 419-434. https://doi.org/10.2307/2215473.

Baillargeon, Renee and Julie De Vos. 1991. "Object Permanence in Young Infants: Further Evidence." Child Development 62(6): 1227-1246. https://doi.org/10.2307/1130803.

Barrett, Justin. 1999. “Theological Correctness: Cognitive Constraints and the Study of Religion." Method and Theory in the Study of Religion 11(4): 325-339. https://doi.org/10.1163/157006899X00078.

Barrett, Justin. 2004. Why Would Anyone Believe in God? New York: Altamira Press.

Barrett, Justin. 2012. Born Believers: The Science of Children's Religious Belief. New York: Free Press.

Barrett, Justin and Frank Keil. 1996. "Conceptualizing a Nonnatural Entity: Anthropomorphism in God Concepts." Cognitive Psychology 31: 219-247. https://doi.org/10.1006/cogp.1996.0017.

Barrett, Justin and Rebekah Richert. 2003. "Anthropomorphism or Preparedness? Exploring Children's Concept of God." Review of Religious Research 44(3): 300-312. https://doi.org/10.2307/3512389.

Boyd, Robert. 2018. A Different Kind of Animal: How Culture Transformed Our Species. Princeton, NJ: Princeton University Press. https://doi.org/10.1515/9781400888528.

Boyer, Pascal. 2001. Religion Explained: The Evolutionary Origins of Religious Thought. New York: Basic Books.

Boyer, Pascal. 2019. "Informal Religious Activity Outside Hegemonic Religions: Wild Traditions and Their Relevance to Evolutionary Models." Religion, Brain, and Behavior https://doi.org/10.1080/2153599X.2019.1678518.

Boyer, Pascal and Charles. 2001. "Cognitive Templates for Religious Concepts: Cross-Cultural Evidence for Recall of Counter-intuitive Representations." Cognitive Science 25: 535-564. https://doi.org/10.1207/s15516709cog2504 2.

it is clearly possible to be born into a human developmental context without becoming a sinner, I would answer that Christ had resources at his disposal for counteracting the warping effects of that context that we do not have. I thank Kutter Callaway for raising the issue. 
Beatrice, Pier Franco. 2013. The Transmission of Sin: Augustine and the Pre-Augustinian Sources. Trans. Adam Kamesar. New York: Oxford University Press. https://doi.org/10.1093/acprof:oso/9780199751419.001.0001.

Cosmides, Leda and John Tooby. 1992. "Cognitive Adaptations for Social Exchange." The Adapted Mind. Eds. Jerome Barkow, Leda Cosmides, and John Tooby. New York: Oxford University Press. 163-228.

Crisp, Oliver. 2015. “On Original Sin." International Journal of Systematic Theology 17(3): 252-266. https://doi.org/10.1111/ijst.12107.

Crisp, Oliver. 2020. "A Moderate Reformed View." Original Sin and the Fall: Five Views. Eds. Jim Stump and Chad Meister. Downers Grove, Ill.: Intervarsity Press. 35-54.

Francis, Richard. 2011. Epigenetics: How Environment Shapes Our Genes. New York: Norton.

Gendler, Tamar Szabo. 2000. "The Puzzle of Imaginative Resistance." The Journal of Philosophy 97(2): 55-81. https://doi.org/10.2307/2678446.

Haidt, Jonathan, Silvia Helena Koller, and Maria Dias. 1993. "Affect, Cultural, and Morality, or Is it Wrong to Eat Your Dog?" Journal of Personality and Social Psychology 65(4): 613-628. https://doi.org/10.1037/0022-3514.65.4.613.

Heider, Fritz and Marianne Simmel. 1944. "An Experimental Study of Apparent Behavior." The American Journal of Psychology 57(2): 243-259. https://doi.org/10.2307/1416950.

Henrich, Joseph. 2016. The Secret of Our Success: How Culture is Driving Human Evolution, Domesticating Our Species, and Making Us Smarter. Princeton, NJ: Princeton University Press. https://doi.org/10.1515/9781400873296.

Kahneman, Daniel. 2011. Thinking Fast and Slow. New York: Farrar, Straus, and Giroux.

Laland, Kevin. 2017. Darwin's Unfinished Symphony: How Culture Made the Human Mind. Princeton, NJ: Princeton University Press. https://doi.org/10.1515/9781400884872.

Liao, Shen-yi, Nina Strohminger, and Chandra Sekhar Sripada. 2014. "Empirically Investigating Imaginative Resistance." British Journal of Aesthetics 54(3): 339-355. https://doi.org/10.1093/aesthj/ayu027.

McCauley, Robert. 2011. Why Religion is Natural and Science is Not. New York: Oxford University Press.

McCall, Thomas. 2019. Against God and Nature: The Doctrine of Sin. Wheaton: Crossway.

McFarland, Ian. 2010. In Adam's Fall: A Meditation on the Christian Doctrine of Original Sin. Oxford: Wiley-Blackwell. https://doi.org/10.1002/97814443327656. 
Norenzayan, Ara. 2013. Big Gods: How Religion Transformed Cooperation and Conflict. Princeton, NJ: Princeton University Press. https://doi.org/10.1515/9781400848324. Robinson, Lucy, Lucy Stevens, Christopher Threapleton, Jurgita Vainiute, Hamish Mcallister-Williams, and Peter Gallagher. 2012. "Effects of Intrinsic and Extrinsic Motivation On Attention and Memory." Acta Psychologica 141(2): 243-249. https://doi.org/10.1016/j.actpsy.2012.05.012.

Slone, D. Jason (2004). Theological Incorrectness: Why Religious People Believe What They Shouldn't. New York: Oxford University Press. https://doi.org/10.1093/0195169263.001.0001.

Simons, Daniel and Christopher Chabris. 1999. "Gorillas in Our Midst: Sustained Inattentional Blindness for Dynamic Events." Perception 28(9): 1059-1074. https://doi.org/10.1068/p281059.

Spelke, Elizabeth and Katherine Kinzler. 2007. "Core Knowledge." Developmental Science 10(1): 89-96. https://doi.org/10.1111/j.1467-7687.2007.00569.x.

Striano, Tricia and Philippe Rochat. 2000. "Emergence of Selective Social Referencing in Infancy." Infancy 1(2): 253-264. https://doi.org/10.1207/S15327078IN0102 7.

Tomasello, Michael. 2019. Becoming Human: A Theory of Ontogeny. Cambridge, Mass.: Belknap Press. https://doi.org/10.4159/9780674988651.

Zuckerman, Phil. 2020. Society Without God: What the Least Religious Nations Can Tell Us About Contentment. New York: New York University Press.

Published Online: February 15, 2022 